\title{
Las manzanas en Ocumazo (Jujuy, Argentina) como PARTE DE LA DIVERSIDAD DE CULTIVOS TRADICIONALES: USOS Y PERCEPCIONES
}

\author{
The apples in Ocumazo (Jujuy, Argentina) as part of the diversity \\ OF TRADITIONAL CROPS: USES AND PERCEPTIONS
}

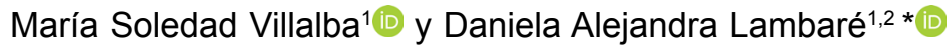

1. Cátedra de Botánica Sistemática y Fitogeografía, Laboratorio de Botánica Sistemática y Etnobotánica (LABOSyE), Facultad de Ciencias Agrarias, Universidad Nacional de Jujuy, Argentina.

2. Instituto de Ecoregiones Andinas (INECOA). CONICET-Universidad Nacional de Jujuy, Argentina.

*alejandralambare@gmail.com

Citar este artículo

VILLALBA, M. S. \& D. A. LAMBARÉ. 2019. Las manzanas en Ocumazo (Jujuy, Argentina) como parte de la diversidad de cultivos tradicionales: usos y percepciones. Bol. Soc. Argent. Bot. 54: 431-449.

DOI: http://dx.doi. org/10.31055/1851.2372.v54. n3.25368

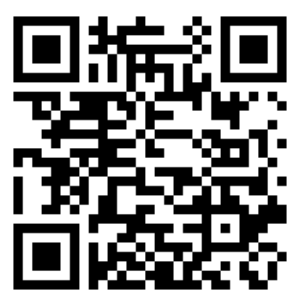

Recibido: 8 Abril 2019

Aceptado: 5 Agosto 2019

Publicado: 30 Septiembre 2019

Editora: Norma Hilgert (D)

\section{SUMMARY}

Background and aims: The introduction of the Euroasiatic fruit trees from the Rosacea's botanical family in northwestern Argentina during the Colonial period, gave rise to processes of cultural selection and diversification, being recognized as their own crops by the local communities that inhabit the Quebrada de Humahuaca. The objective of this work is to present the diversity of ethno-varieties "apple" (Malus domestica, Rosaceae), their uses and the locally perceived attributes that are used for their differentiation in the community of Ocumazo (Department of Humahuaca, Jujuy, Argentine).

M\&M: The ethnobotanical methodology, mainly qualitative, is what allowed the development of this work, which was carried out between 2016-2018.

Results: The producers interviewed (28) establish the presence of (15) ethnovarieties of "apples" used in food and for the production of products often marketed locally. The fruit is the main vegetal organ cited to define the criteria or cultural descriptors used for the differentiation of the ethno-varieties.

Conclusion: The use, the way of selection, conservation, its consideration as part of the diversity of "Andean fruits" and the presence in different religious and celebration instances, define the relevant role of this crop of Eurasian origin for the local population, which allows to promote the conservation of main economic activities such as agriculture and its food autonomy.

\section{KEY WORDS}

Biocultural, ethnobotanical diversity, fruit trees of La Quebrada, Rosaceae.

\section{RESUMEN}

Introducción y objetivos: La introducción de los frutales Euroasiáticos de la familia botánica de las Rosáceas en el noroeste argentino durante el periodo Colonial, dio lugar a procesos de selección cultural y diversificación, siendo reconocidos como cultivos propios por las comunidades locales que habitan en la Quebrada de Humahuaca. El objetivo de este trabajo es presentar la diversidad de etnovariedades de "manzanas" (Malus domestica, Rosaceae), sus usos y los atributos localmente percibidos que se emplean para su diferenciación en la comunidad de Ocumazo (Departamento de Humahuaca, Jujuy, Argentina).

M\&M: La metodología etnobotánica, principalmente de corte cualitativo es la que permitió el desarrollo de este trabajo, el cual se llevó a cabo entre el año 20162018.

Resultados: Los productores entrevistados (28) establecen la presencia de (15) etnovariedades de "manzana" empleadas en alimentación y para la elaboración de productos muchas veces comercializados localmente. El fruto es el principal órgano vegetal citado para definir los criterios o descriptores culturales empleados para la diferenciación de las etnovariedades.

Conclusiones: El uso, la forma de selección, conservación, su consideración como parte de la diversidad de "frutas andinas" y la presencia en distintas instancias religiosas y de celebración, definen el papel relevante de este cultivo introducido para el poblador local, que a su vez le permite promover la conservación de actividades económicas principales como las agrícolas y su autonomía alimentaria.

\section{Palabras clave}

Diversidad biocultural, etnobotánica, frutales de la Quebrada, Rosaceae. 


\section{INTRODUCCIÓN}

Este trabajo se inscribe en la etnobotánica, considerada como campo inter y transdisciplinar (Crivos, 2010), entendida como el estudio de las relaciones planta - humanos incluidos en ecosistemas dinámicos con componentes naturales y sociales; es decir el estudio del uso de las plantas contextualizado (Alcorn, 1995). Desde esta perspectiva, estudia -entre otros temas tanto utilitarios como simbólicos- la percepción y manejo local que las personas realizan sobre los recursos de su ambiente y, en base a ello se propone generar interpretaciones científicas que den privilegio a la visión y a la voz de las poblaciones locales sobre sus propias prácticas (Toledo, 1990).

Una de sus herramientas conceptuales es el Conocimiento Botánico Tradicional (CBT), conjunto de saberes y prácticas, generados y seleccionados por el continuo contacto entre los seres humanos y los elementos que forman el ambiente (Berkes et al., 2000). El CBT se acumula a lo largo del tiempo, se conserva mediante la práctica, de naturaleza dinámica, pudiendo transmitirse de una generación a otra (Berkes, 1999; Luna-Morales, 2002; Pochettino \& Lema, 2008). El complejo kosmos-korpus-praxis propone que las prácticas y uso de plantas (praxis) ocurren y cobran sentido cuando se las enlaza a un cuerpo de conocimientos (korpus) y creencias (kosmos) (Toledo, 2002). Así, la praxis juega un rol importante en la conservación de las plantas ya que se materializa en la toma de decisiones y los criterios de selección de la variabilidad (Stampella et al., 2013).

En el Noroeste de Argentina, principalmente en la Quebrada de Humahuaca, la agricultura es el sistema productivo de mayor relevancia para los grupos familiares, siendo una alternativa de subsistencia que se realiza desde la antigüedad. Esta actividad combina la conservación de cultivos andinos con aquellas plantas que, por ciertos fenómenos globales ocurridos en la historia, como el ingreso de frutales euroasiáticos en América a partir de finales del siglo $\mathrm{XV}$, se incorporaron a la biodiversidad local. Dentro de este elenco de plantas se pueden citar las "manzanas" (Malus domestica Borkh., Rosaceae). En la actualidad este frutal y otros pertenecientes a las Rosáceas, son una alternativa para la obtención de forraje, combustible, sombra, medicina, aunque se destacan como una fuente importante de alimento, tanto tradicional como novedoso/innovador. Estos frutales están integrados a espacios y prácticas culturales que caracterizan a las comunidades que habitan la zona y pueden combinarse con la flora autóctona para cubrir una gran diversidad de usos (Lambaré, 2015).

Desde hace tiempo, se empezaron a revalorizar las variedades locales de frutales euroasiáticos (Rosaceae: "manzanos", "perales"-Pyrus communis L.-, "almendros" - Prunus dulcis L.-, "membrillos" -Cydonia oblonga Mill.-, "cerezos", -Prunus avium L.- "ciruelos" -Prunus domestica L.-, "durazneros" - Prunus persica (L.) Batsch-; Rutaceae: "cítricos" -Citrus spp.-; Cucurbitaceae: "melones" -Cucumis melo L.- y Moraceae: "higueras" -Ficus carica L.-), introducidos tempranamente en América y que se encuentran tanto cultivados como espontáneos en diferentes países como Brasil (Shanley et al., 2012), Perú (Pearregaard, 1994), España (Herrero, 1964; Rivera-Nuñez et al., 1997; Pereira-Lorenzo et al., 2001; Martín, 2010; Sierra del Rincón, 2010; SanzGarcía, 2011; Egea-Fernández et al., 2014), México (Rosales-Bustamante et al., 2009), Chile (Rosales, 1877; Lacoste et al., 2015; Castro, 2016; Salamanca, 2017; Castro et al., 2018) y Argentina (Stampella et al., 2013, 2014; Hilgert et al., 2014; Lambaré, 2014, 2015; Lambaré et al., 2015). En general, estos trabajos resaltan los conocimientos, clasificaciones, prácticas de manejo, usos, participación de los sistemas tradicionales de intercambio, selección y conservación de esta agrobiodiversidad que los grupos humanos implementaron y que en la actualidad forma parte de su cultura.

Entre los antecedentes bibliográficos sobre Malus domestica, desde el punto de vista etnobotánico, destaca el trabajo de Rivera-Nuñez et al. (1997). En esta publicación detallan y describen etnotaxa de Malus (categorías subespecíficas según las clasificaciones locales) señalando características del fruto y planta, época de maduración, duración del fruto, importancia cultural, usos y su presencia en distintos rituales locales. Asimismo, en la Reserva la Sierra el Rincón (España) se realizó un catálogo de variedades tradicionales de este frutal, donde además se detallan diferentes preparaciones y festejos patrimoniales relacionados a la diversidad identificada (Sierra del Rincón, 2010).

Otras investigaciones -empleadas como base conceptual para nuestro estudio- dan cuenta de la presencia de cítricos (Citrus spp.) en Argentina, específicamente en el sur de Misiones (Stampella, 


\section{S. Villalba y D. A. Lambaré - Las manzanas en Ocumazo (Jujuy): usos y percepciones}

2015). En este estudio, desde un abordaje interdisciplinario, se identificaron 9 etnoespecies que incluyen 30 etnovariedades, diferenciadas por 25 descriptores organolépticos (morfológicos y sensoriales) y agronómicos (fisiológicos y ecológicos). Asimismo para el NOA, Lambaré (2015) reconoció un conjunto de 9 etnovariedades de "durazno" en comunidades rurales. Éstas se distinguen entre sí por el carácter de adherencia del endocarpo y coloración del epicarpo, además presentan usos específicos como consumo directo, elaboración de dulces y conservas o deshidratados, estando presente en instancias de celebraciones y ferias de intercambio.

Este estudio plantea una perspectiva que va más allá del concepto de cultivo-introducido, donde la aplicación del marco teórico aportado por la Etnobotánica resulta un eje de consideración que permite la identificación de taxa locales, como alternativa para caracterizar la relación grupo humano=planta-ambiente y generar conceptos novedosos relacionado a la Etnotaxonomía (Stampella, 2015). En referencia a ello, la diversidad puede ser reconocida a nivel global -“cultivariedades" según el Código Internacional de Nomenclatura de Plantas Cultivadas (Brickell et al., 2009)-, o tratarse de discontinuidades establecidas localmente, a la que denominaremos etnoespecies o etnovariedades según sea el caso (Lambaré, 2015; Stampella, 2016). Para el presente estudio la denominación de etnotaxa se emplea para referirse colectivamente a las categorías locales, por lo que la etnovariedad queda definida como un tipo particular de cultivariedad, caracterizada por un contexto cultural tradicional y temporal, por un atributo o combinación de atributos siendo diferenciables, uniformes y estables (RiveraNúñez et al., 1997). Estas etnovariedades -también denominadas landraces (razas locales)- están caracterizadas por sus adaptaciones a las condiciones climáticas, edáficas locales y a las prácticas culturales; lo que redunda en características morfofisiológicas particulares (Harlan, 1992). Esta serie de discontinuidades, percibidas como diferentes, conforman la riqueza de etnovariedades sobre la cual acciona la selección cultural (Berlin, 1992; Lambaré \& Pochettino, 2012). La cual es percibida (reconocida y diferenciada) a partir de criterios, descriptores o atributos que aluden a características morfológicas, algún aspecto ecológico, agronómico o utilitario de la planta o partes de la misma (hojas o fruto) (Stampella, 2015).

En otro orden, desde el punto de vista de su valoración, estos frutales se consideran especies alternativas o subutilizadas (NUS por su sigla en inglés), entendiéndose como aquellas especies o variedades domesticadas con usos limitados o particulares de importancia para determinados grupos humanos (Hernández-Bermejo, 2013). Ciertamente, estas especies que son parte de la dieta de indígenas y campesinos, han aportado nutrientes, medicina natural y su adaptación a sistemas de bajos insumos favorecieron la sostenibilidad del sistema agrícola, por lo que retomar su importancia agrícola y social puede ser una alternativa hacia la búsqueda de la autonomía de los pueblos (Bravo et al., 2017). Es así que muchos de estos cultivos y sus productos derivados podrían generar importantes beneficios, no sólo en la alimentación local, sino también en instancias de comercialización reconocidos como "productos autóctonos con identidad de territorio". Éstos recursos que conforman la gastronomía local, tienen un valor socio-cultural que identifica y caracteriza al pueblo que los cultiva y produce, dando lugar a la promoción del patrimonio biocultural (Folgado-Fernández et al., 2017).

Los conceptos tratados hasta aquí, como el de etnovariedad, son generalmente relegados en otras escalas de análisis, siendo relevante en este espacio como referencia para la comparación, dado que el objetivo de este trabajo es presentar la diversidad de "manzanas" en una comunidad rural de la Quebrada de Humahuaca, así como los criterios que permiten su caracterización, diferenciación y la valoración local de las distintas etnovariedades.

Las preguntas que guían esta propuesta son ¿Cómo perciben este cultivo los pobladores desde la perspectiva de su origen? ¿Cómo se relaciona la diversidad vegetal con la diversidad de usos? ¿Qué diferencias y similitudes existen respecto de la caracterización y valoración de cada etnovariedad?

\section{Materiales y Métodos}

\section{Área de estudio}

Se efectuaron trabajos de campo en una comunidad asentada en la Quebrada de Humahuaca, Ocumazo (Departamento de Humahuaca, Provincia de Jujuy) (Fig. 1). Desde 


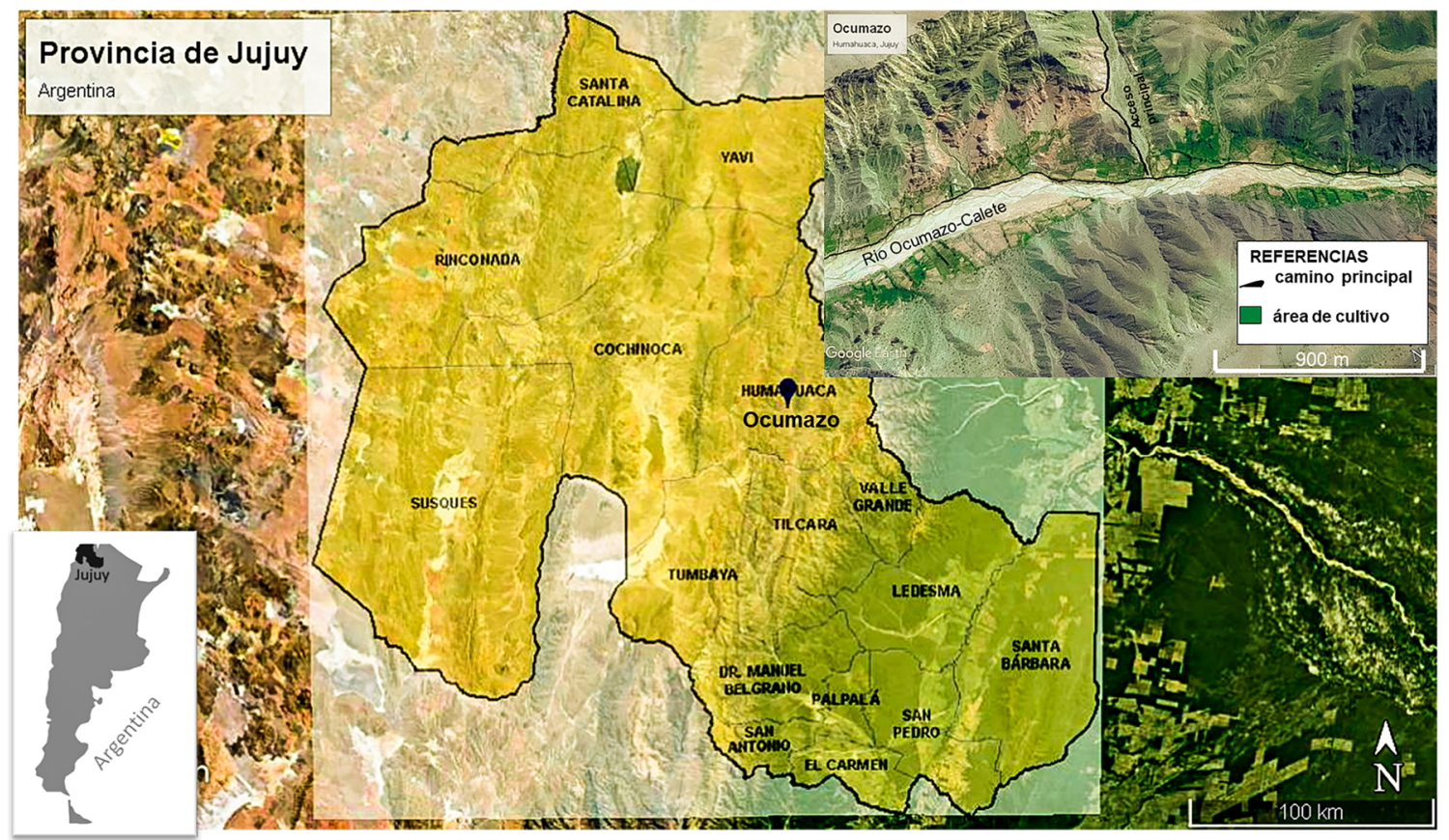

Fig. 1. Área de trabajo: Localidad de Ocumazo en la Quebrada de Humahuaca, Jujuy.

el punto de vista fitogeográfico pertenece a la Provincia Prepuneña, cuya vegetación está compuesta por especies arbustivas, como Gochnatia glutinosa (D. Don) Hook. \& Arn., Senna crassiramea (Benth.) H.S. Irwin \& Barneby, Aphyllocladus spartioides Wedd., Caesalpinia trichocarpa Grised., Proustia cuneifolia D. Don, Cercidium andicola Griseb., Chuquiraga erinacea D. Don, Zuccagnia punctata Cav., Adesmia inflexa Griseb., Krameria lappacea (Dombey) Burdet \& B.B. Simpson, Baccharis boliviensis (Wedd.) Cabrera, Lycium tenuispinosum Miers, L. ciliatum Schltdl., Junellia juniperina (Lag.) Moldenke, Justicia floribunda (C. Koch) Wassh., Bulnesia schickendantzii Hieron. ex Griseb., Bougainvillea spinosa (Cav.) Heimerl, mezcladas con cardonales de Trichocereus atacamensis (Phil.) Backeb. y T. terschecki (Parm. ex Pfeiff.) Britton \& Rose (Cabrera, 1976). Predomina un clima semidesértico con escasas precipitaciones concentradas en el período estival (Paoli et al., 2002). Las temperaturas medias diarias oscilan entre una máxima de $24{ }^{\circ} \mathrm{C}$ y $2,3{ }^{\circ} \mathrm{C}$ de mínima con una amplitud media anual de $19.6^{\circ} \mathrm{C}$ (Difrieri, 1978).
Ocumazo, conocida comúnmente como valle escondido, es una comunidad originaria de los Omaguaca que se ubica $18 \mathrm{~km}$ al este de la ciudad de Humahuaca, a una altitud de $3.050 \mathrm{msnm}$ (S $23^{\circ} 14^{\prime} 13,0$ " W $\left.065^{\circ} 16^{\prime} 41,5^{\prime \prime}\right)$. Este grupo étnico, denominado Omaguaca -que en aymara significa agua sagrada-, se distribuía al este de la Puna, sobre el eje del Río Grande y quebradas afluentes y tenían los sitios agrícolas en el fondo de los valles y en áreas elevadas; además eran hablantes de lenguas Kunza y Quechua (García-Moritán \& Cruz, 2011), las que en la actualidad no se emplean entre los pobladores del lugar.

El poblado de Ocumazo está asentado a ambos lados de una estrecha quebrada surcada por un río de curso permanente, cuyo nombre cambia de acuerdo a la comunidad que atraviesa, constituyendo un afluente del margen izquierdo del río Grande de la Quebrada de Humahuaca (Fig. 2). Sus pobladores viven de la agricultura, predominando principalmente la producción de distintas hortalizas, legumbres, cereales y frutales ("manzanas", "peras" y "duraznos"), integran la Red Argentina de Turismo Rural Comunitario (RATuRC), orientada por la Secretaría de Turismo de la Provincia y el 


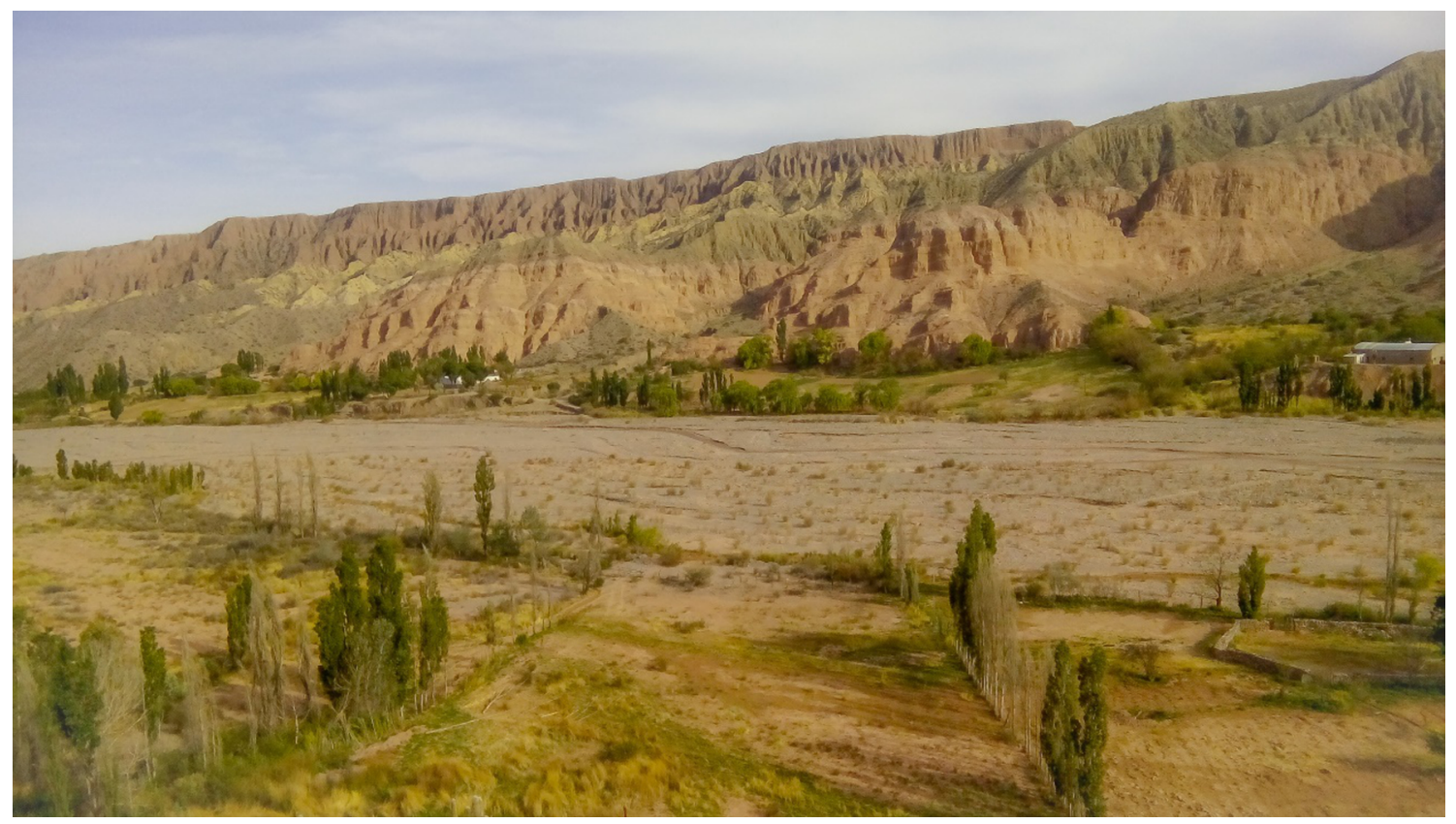

Fig. 2. Comunidad de Ocumazo (Dpto. de Humahuaca, Jujuy).

Ministerio de Turismo de la Nación, alternativa para exponer las distintas actividades culturales que realizan tales como, el modo de labranza (por medio de un arado romano tirado por yuntas de bueyes), la presencia de un molino hidráulico utilizado para triturar los cereales producidos, así como los distintos festivales tradicionales, paisajes naturales y las comidas típicas del lugar.

En esta localidad viven 70 personas (36 familias). Sólo dos a tres familias residen de forma permanente (generalmente los adultos mayores), mientras que las demás tienen sus domicilios en la ciudad de Humahuaca. La que es considerada centro de abastecimiento y como una alternativa para trasladar la familia o a los jóvenes para estudiar. Las familias por lo general regresan a la comunidad los fines de semana, en épocas de cosecha, festividades, asambleas o por el arrendado de la tierra a personas ajenas a la comunidad (Muñoz, 2014).

\section{Metodología}

Se trabajó con 28 personas (11 mujeres y 17 hombres) $-40 \%$ de la población-. Durante las primeras instancias se obtuvo el consentimiento previamente informado para la participación en la investigación y difusión de los resultados.
En este trabajo se utilizó metodología propia de la etnobotánica cualitativa. Se realizaron observaciones participantes y entrevistas abiertas, semi-estructuradas y en profundidad a pobladores seleccionados previamente mediante muestreo diferencial; es decir a aquellos pobladores reconocidos localmente por su saber especializado (Cotton, 1998; Albuquerque et al., 2010). Se implementaron caminatas etnobotánicas. Todas estas instancias se llevaron a cabo en los distintos espacios que recorre el productor, como el rastrojo (lugar del terreno destinado para el cultivo de especies de temporada), la quinta (nombre que adquiere todo el campo o terreno perteneciente a una familia), la toma (lugar del cual se adquiere el recurso agua para el riego de los terrenos), el patio (espacio alrededor de la casa principal), centro vecinal (salón empleado para realizar las reuniones mensuales y eventos sociales de la comunidad) y los domicilios familiares en la ciudad de Humahuaca.

Las entrevistas y las visitas a los espacios de cultivo se realizaron a partir del año 2016 y se completaron en el 2018, realizándose en el estadio reproductivo y vegetativo del cultivo. Durante las entrevistas se indagó sobre la diversidad 
percibida -entendida como discontinuidades que se presentan, perciben y aprecian en la naturaleza y que configuran la riqueza de una determinada especie sobre la que opera la selección cultura- (Berlin, 1992; Stampella, 2016). Se indagó asimismo, sobre los criterios, descriptores y apreciaciones locales empleados para la clasificación y diferenciación de las etnovariedades. Además, se registraron los usos, las preparaciones obtenidas y las valoraciones personales sobre la diversidad identificada. Las entrevistas se registraron en grabaciones digitales y cuadernos de campo. Asimismo, se registró la diversidad presente a partir de fotografías. Los nombres de las etnovariedades fueron tomados de forma complementaria de los rótulos o etiquetas presentes en instancias de comercialización en los que se participó. Se recolectaron frutos correspondientes a cada etnovariedad, mediante el reconocimiento directo en campo con la ayuda del poblador local. Posteriormente, las muestras fueron acondicionadas y se depositaron en el Laboratorio de Botánica Sistemática y Etnobotánica perteneciente a la Cátedra de Botánica Sistemática y Fitogeografía de la Facultad de Ciencias Agrarias (UNJu), con el fin de garantizar su conveniente documentación (Martin, 2001).

\section{Análisis de la información}

Se confeccionó una tabla con el listado de especies tratadas, sus nombres vernáculos y los distintos criterios de identificación local descriptos por los colaboradores (Tabla 1). Se calcularon desviación estándar y frecuencia de citas.

Material examinado. Malus domestica Borkh. ARGENTINA. Jujuy. Depto. Humahuaca, Ocumazo. Villalba, M. S., 14-II-2017, "Grani”, M-CBSF 846 (frutos); 15-II-2017, "Deliciosa chiquita", M-CBSF 847 (frutos); "Criolla", M-CBSF 848 (frutos); "Pera", M-CBSF 849 (frutos); "Deliciosa grande", M-CBSF 850 (frutos); "Verde", M-CBSF 851 (frutos); "Inverniza", M-CBSF 852 (frutos); 16-II-2017, "Melona", M-CBSF 853 (frutos); 06-V-2017, "Ojenrri”, M-CBSF 854 (frutos); "Gran esmitt", M-CBSF 855 (frutos); "Del bien y del mal", M-CBSF 856 (frutos); 10-VI-2017, "Roja", M-CBSF 857 (frutos); “Can”, M-CBSF 858 (frutos).

\section{Resultados}

\section{La diversidad percibida}

En esta localidad el cultivo de "manzana" resulta ser el que predomina y se observa en asociación con otros frutales como "duraznos", "peras", "ciruelos", "nueces" (Juglans regia L.), "membrillos" y cultivos hortícolas como "papa" (Solanum tuberosum L. subsp. andigenum (Juz. \& Bukasov) Hawkes), "maíz" (Zea mays L.), "haba" (Vicia faba L.), "quínoa" (Chenopodium quinoa Willd.), "trigo" (Triticum aestivum L.), "zanahoria" (Daucus carota L.), "zapallo" (Cucurbita spp.), "zapallito" (Cucurbita spp.), "cayote" (C. ficifolia Bouché), "arveja” (Pisum sativum L.), "rabanito" (Raphanus sativus L.), "remolacha" (Beta vulgaris L. var. vulgaris), "tomate" (Solanum lycopersicum L.), "pimiento" (Capsicum annum L.), "acelga" (B. vulgaris L. var. cicla L.), "lechuga" (Lactuca sativa L.), "cebada" (Hordeum vulgare L.).

La diversidad percibida está constituida por un total de 15 etnovariedades de "manzanas" en Ocumazo. Todas pertenecen a la especie botánica M. domestica y son agrupadas localmente bajo el término de "manzana", el mismo va acompañado de diversos epítetos, que hacen referencia a: su origen (como por ejemplo "Criolla"), a la época de cosecha ("Inverniza"), o algún criterio organoléptico como la morfología o el sabor ("Deliciosa grande") (Fig. $3)$.

En la Tabla 2 se resume la diversidad definida para la localidad y los criterios que permiten su descripción. Estos criterios se agrupan en tres categorías: organolépticos (morfológico y sensorial); utilitarios (alimenticio y otros usos); agronómicos (relacionado con la época de floración/ cosecha y duración de la fruta pos-cosecha). Estas categorías o descripciones abarcan criterios principalmente relacionados con el fruto.

Todas las etnovariedades se encuentran bajo cultivo, sin identificar ejemplares espontáneos. Predominan las que se reproducen por semilla, con una sola etnovariedad "Criolla", que se multiplica de forma asexual por esquejes. De acuerdo al relato local, la historia de ingreso y la diversidad actual del cultivo deriva de dos vertientes. Las primeras, etnovariedades consideradas como autóctonas o las de aquí, son resultado de la introducción de estos frutales en 
Tabla 1. Diversidad, origen y tiempo de ingreso a la comunidad de Ocumazo.

\begin{tabular}{|c|c|c|}
\hline $\begin{array}{l}\text { Grupos reconocidos de } \\
\text { acuerdo a su origen }\end{array}$ & Etnovariedad & Procedencia y tiempo de ingreso \\
\hline \multirow{4}{*}{ “autóctonas" } & "Criolla" & Autóctona ("las de aquí")- aprox. de 100 años \\
\hline & "Pera" & Autóctona ("las de aquí")- aprox. de 100 años \\
\hline & "Inverniza" & Autóctona ("las de aquí")- aprox. de 100 años \\
\hline & "Melona" & Autóctona ("las de aquí")- aprox. de 100 años \\
\hline \multirow{11}{*}{$\begin{array}{c}\text { "coloradas", } \\
\text { "mendocinas", "las del } \\
\text { sur" o "abajeñas". }\end{array}$} & "Deliciosa chiquita" & Mendoza- aprox. de 60 años \\
\hline & "Deliciosa grande" & Rio Negro/Mendoza- aprox. de 60 años \\
\hline & "Amarilla" & aprox. 12 años \\
\hline & "Can" & Rio Negro - aprox. 12 años \\
\hline & "Rayada" & Rio Negro - aprox. 12 años \\
\hline & "Roja" & Rio Negro - aprox. 12 años \\
\hline & "Verde" & Mendoza /Rio Negro (sin registro) \\
\hline & "Gran esmitt" & Rio Negro/San Pedro de Bs. As.- aprox. 10 años \\
\hline & "Grani” & Rio Negro - aprox. 4 años \\
\hline & "Del bien y del mal" & aprox. de 54 años \\
\hline & "Ojenrri" & Rio Negro - aprox. 10 años \\
\hline
\end{tabular}

la Quebrada de Humahuaca durante el Período Colonial a partir del siglo XVI, las que ingresan y se establecen en Ocumazo recién en el siglo XX. El ingreso aproximado es de 100 años, entre ella se cita la "Criolla" "Inverniza", "Melona", "Pera". Don C.M. (77 años) comenta sobre la manzana "Criolla": "es riquísima, esa la buscan mucho en el campo, esa manzana les gusta a todos porque esa ya viene de antes", "es la que más hay aqui en Ocumazo, y es la mejor, la más querida, todos la compran a esa". Don F.M. (68 años) relata: "la inverniza esa, es como pie porque es una planta muy autóctona de la zona y deber haber sido unas de las primeras plantas que habia aqui".

La otra vertiente de ingreso es actual y consiste en material genético de variedades comerciales, incorporadas hace poco tiempo en la comunidad (12 años aproximadamente). Estos materiales llegaron a la zona de la mano de algún familiar desde otra zona de la Argentina, como el Sur o Mendoza, o por técnicos de entidades como el INTA (Instituto Nacional de Tecnología Agropecuaria), las que se preservar bajo las mismas prácticas de manejo y selección local. Este grupo de etnovariedades recientemente introducidas se las reconoce como "coloradas", "mendocinas", "las del sur" o "abajeñas". Ejemplo de ello es la etnovariedad “Grani”, “Ojenrri” (Tabla 2).
Estas etnovariedades (las autóctonas y las de reciente inserción) son reconocidas por los ocumaceños como "frutas criollas" o "frutas andinas". El sentido de apropiación y la profundidad temporal de este cultivo por algunos entrevistados aparece en citas como: "porque esas han sido las primeras manzanas que han traído aquí, no sé de adonde habrán traído mis padres, pero son las primeras por eso le decimos criollas" (don S.M., 76 años), "la criolla esa, es antigua. Mi papá llevó plantas de no sé dónde, no dijo mi papá. -Me traje unas plantitas de manzanas, nomás dijo. No teníamos nada, compró la finca ahi en Ocumazo. Él era comprador, entonces ahí se hicieron sus casitas, se pusieron sus plantitas, ya hace años. Yo ya conocí cuando yo tenía 16 años. Cuando mi papa murió, ya tenía las manzanas: la larga (= "Pera") y la criolla, nada más" (doña P.A., 85 años).

El promedio de etnovariedades cultivadas por familia es de 4 , con un desvío estándar de 1,8; siendo 2 la menor cantidad hallada y 8 la mayor. Las etnovariedades más frecuentemente citadas son: "Criolla" (81\%), "Deliciosa grande" (58\%), "Verde" (42\%), "Inverniza" (35\%), "Melona" (27\%) y "Deliciosa chiquita" (15\%), de las cuales tres etnovariedades son las reconocidas como las "autóctonas". 

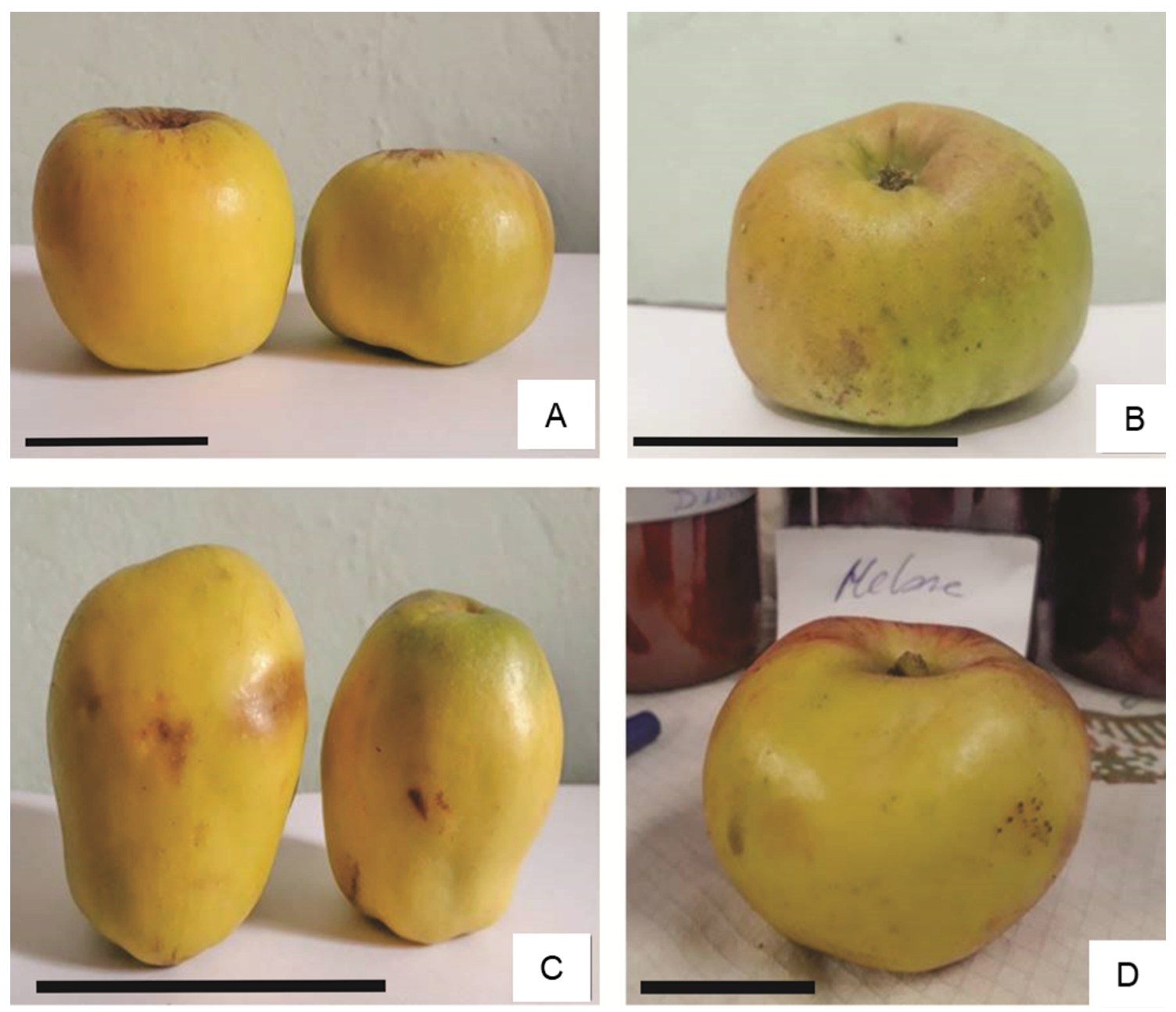

Fig. 3. Etnovariedades reconocidas como propias del lugar "las de aquí". A: "Criolla". B: "Inverniza". C: "Pera". D: "Melona". Escala: $5 \mathrm{~cm}$.

\section{Los atributos en el relato local}

El reconocimiento de las etnovariedades de "manzanas" se basa principalmente en las características del fruto; son escasas las menciones relacionadas a caracteres vegetativos de la planta que permita la diferenciación de la diversidad presente. Los entrevistados que señalan estos caracteres vegetativos, los utilizan para realizar comparaciones entre las autóctonas (específicamente la "Criolla") y las recientemente introducidas, "coloradas", "mendocinas", "las del sur" o "abajeñas".

En la Tabla 3 se presentan todos los descriptores utilizados por los ocumaceños, para la caracterización de las etnovariedades. Se puede apreciar que los descriptores más citados fueron: color (27), sabor (25), consistencia (21), tamaño (19) y forma (14).

Como se estableció, los criterios utilizados por los agricultores están basados en apreciaciones principalmente organolépticas que poseen del fruto de las distintas etnovariedades, así aparecen criterios que combinan expresiones generalizadas con otras de origen local. Por ejemplo, para el criterio sabor aparecen las expresiones: "dulce, menos ácida" (etnovariedad "Criolla"), "bien dulce, algo ácida", "mimosa" (dulce) (etnovariedad "Deliciosa grande"), "bien dulce antes de cocer" (madurar) (etnovariedad "Melona”), "ácida y amarga, 


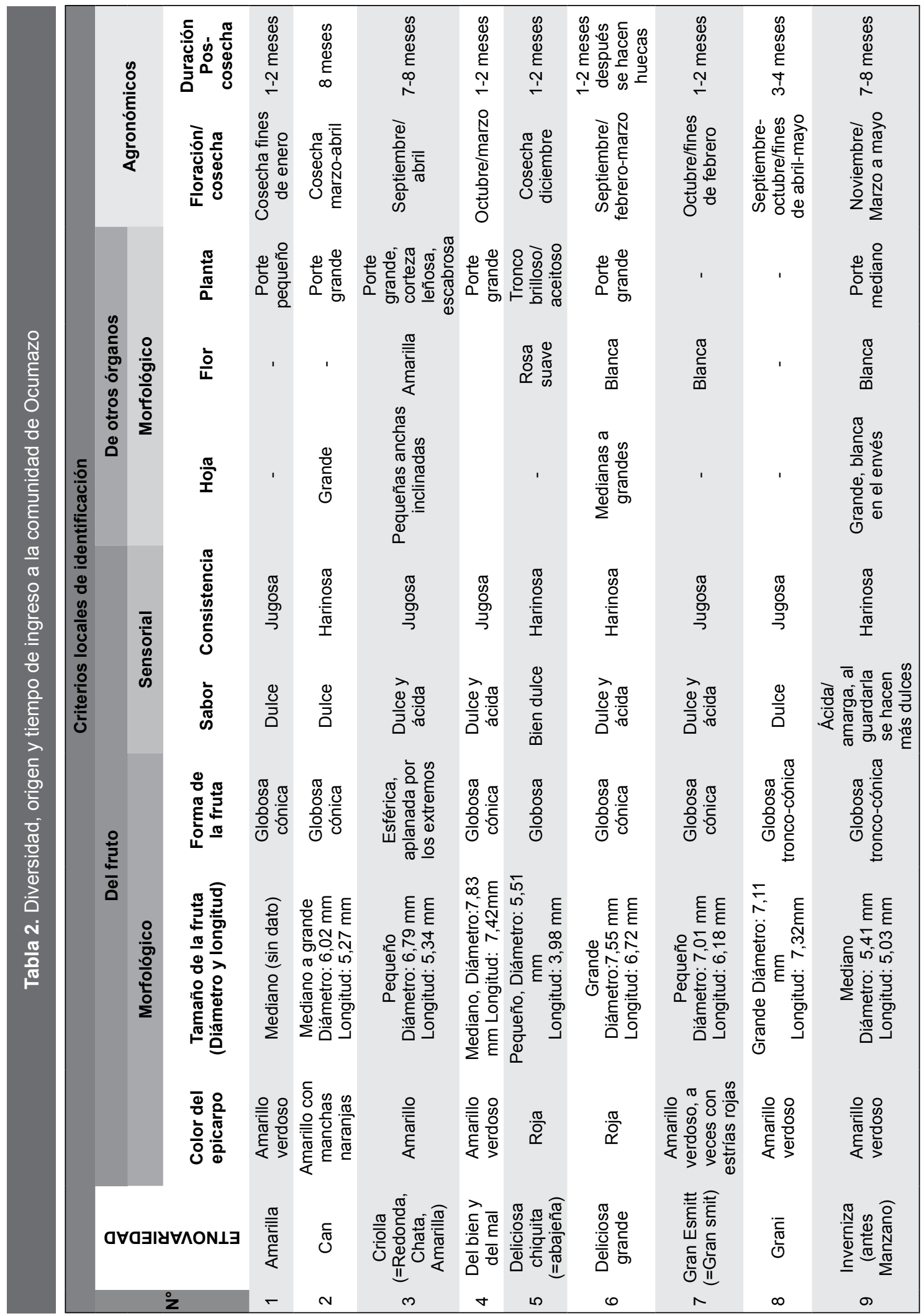


Bol. Soc. Argent. Bot. 54 (3) 2019

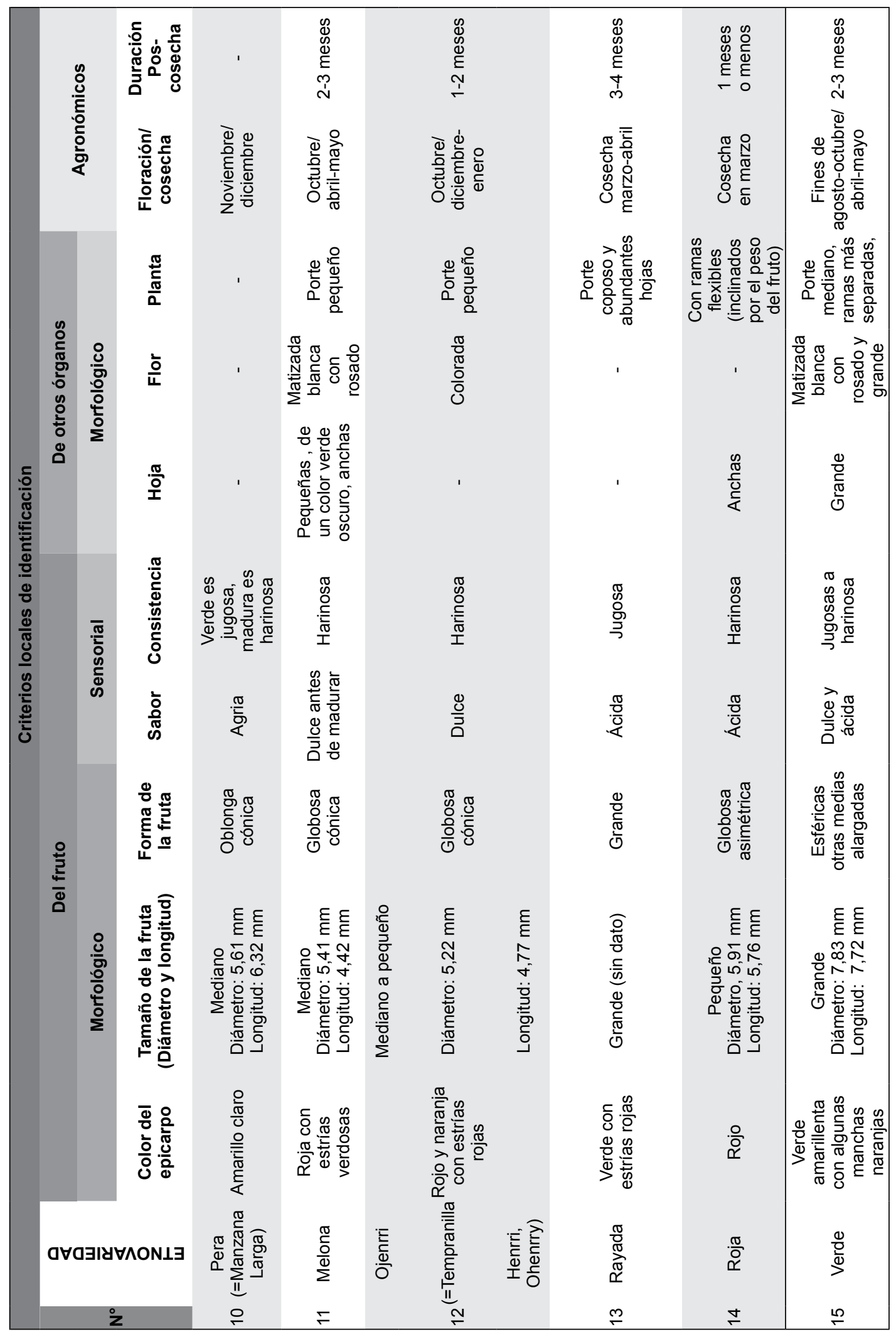




\section{S. Villalba y D. A. Lambaré - Las manzanas en Ocumazo (Jujuy): usos y percepciones}

al almacenarla es más dulce" (etnovariedad "Inverniza"), "media agrita" (agria) (etnovariedad "Pera").

En relación a la consistencia se emplearon términos como "arenosa" (consistencia del fruto debido a la pérdida de turgencia), "aguachenta" o "jugosa" (con gran cantidad de agua en su composición), "blandita", que se combinan entre sí y con distintos grados de intensidad, como por ejemplo "primero es aguachenta, después arenosa" (etnovariedad "Verde"), medio arenosa (etnovariedad "Roja"). El color de la fruta, por su parte, queda clasificado por "amarillenta", "roja" o "colorada" y se combina a la presencia de estrías ("rayas" o "rayitas") de distintas tonalidades: "bien rojita con rayas verdosas" (etnovariedad "Melona"), "verde con rayitas rojas" (etnovariedad "Rayada"), "amarillenta con partes coloradas al cocer" (etnovariedad "Can"). En relación a este criterio también se asocia con el color de otro frutal, por ejemplo: la etnovariedad Verde "es como la pera de agua", también con la época de cosecha: "es verde al cosecharla y cuando se la guarda, se madura y es amarillenta" (etnovariedad "Inverniza"). Se citan referencias que combinan sabor y consistencia: "la criolla es bien agria de chiquita, ya cuando está bien cocinada ya es dulce $y$ jugosa". La forma es un carácter que citan los productores, pero no suele ser tan detallado para toda la diversidad de "manzana", se menciona por ejemplo en referencia a la forma términos como: "es redonda media alargona" ("Deliciosa grande").

Algunas etnovariedades están presentes en celebraciones religiosas y populares andinas. Como ofrenda para el 1 de noviembre (Todos los Santos), para la celebración patronal de la Virgen del Rosario de Ocumazo ( 5 al 15 de octubre), en las de fin de año (Navidad y Año Nuevo) y en las del primero de Agosto (Pachamama). Cuando se preguntó sobre ello, los pobladores respondieron: "sí, cuando hay si para todo santo" (R.F., 75 años), "cuando hay Inverniza esa se pone a la mesa” (S.F., 69 años), "Todo ponemos a la mesa, para la Pachamama también porque es fruta de la tierra” (M.C., 64 años). Además, se identificó que el cultivo posee un valor sentimental o emotivo para cada ocumaceño, ello está relacionado con la presencia de este frutal desde tiempo pasado en la zona, especialmente de la etnovariedad "Criolla". En los relatos se identifica que existe una relación de reciprocidad entre el cultivo y productor, mientras que se obtiene

\begin{tabular}{|c|c|c|}
\hline $\begin{array}{l}\text { Parte de } \\
\text { la planta }\end{array}$ & Descriptor & $\begin{array}{c}\mathrm{N}^{\circ} \mathrm{de} \\
\text { menciones }(\mathrm{n}=28)\end{array}$ \\
\hline \multirow{6}{*}{ Fruto } & Color & 27 \\
\hline & Sabor & 25 \\
\hline & Consistencia & 21 \\
\hline & Tamaño & 19 \\
\hline & Forma & 14 \\
\hline & Espesor del epicarpo & 4 \\
\hline \multirow{6}{*}{ Hoja } & Color & 8 \\
\hline & Tamaño & 8 \\
\hline & Ancho & 4 \\
\hline & Forma & 3 \\
\hline & Inclinación & 1 \\
\hline & Cantidad & 6 \\
\hline \multirow{2}{*}{ Flor } & Color & 7 \\
\hline & Tamaño & 1 \\
\hline \multirow{3}{*}{ Planta } & Porte & 9 \\
\hline & Tronco & 1 \\
\hline & Producción & 1 \\
\hline
\end{tabular}

alimento e insumo para comercializar, el poblador cuida de este cultivo como un miembro más de su familia, con el cual entabla conversaciones en los momentos de soledad o al realizar alguna actividad como riego, poda, abonado: "están ahí, las hablás. Es como una persona, yo veo así, que tienen plantas que no las cuidan. Así, nadie las van a ver, se empiezan a secar. En cambio, si vos las vas a ver se ponen hermosas. Son como un hijo. Vos vas, las hablas, decís: - pachita dame fruta, y dan -cuando uno cree-" (don J. F., 65 años), "es parte de mi familia, si las dejas mucho tiempo se secan, tenés que pasar más tiempo con ellas, podando, regando" (don T.F., 67 años), "toda mi vida, desde que yo he conocido las manzanas, son importantes para mi vida. En mis recuerdos son las preferidas porque no solo me alimentaron, cuando fui adolescente, me ayudaron con mis estudios. Porque papá las llevaba a Ledesma y las vendia" (doña M.F., 73 años). "Toda mi vida, desde que yo he conocido las manzanas, son importantes para mi vida” (M.F., 73 años), “ $y$ 
las manzanas son importantes para mí porque es mi fruta predilecta” (E.M.), "Es una cultura más que todo, porque siempre están para vender, comerlas y para repartir a mi familia” (N.L., 73 años).

\section{Usos tradicionales y preparaciones}

En el ámbito familiar el principal uso es el consumo directo de la fruta como alimento, además se emplea como materia prima para la elaboración de diversos productos en base a la misma (Fig. 4). Se identificaron un total de 18 preparaciones que se obtienen de las distintas etnovariedades. La elaboración de la mayor parte de estos productos está a cargo de las mujeres (45\%), entre los preparados en los que se involucran los hombres (38\%) se citaron dulces, mermeladas, licores y sidra.
En la Fig. 5 se indican la forma de consumo y los preparados que se obtienen de cada etnovariedad. Este gráfico permite visualizar la intensidad de uso que tiene cada etnovariedad en la elaboración de distintos productos. Se puede observar que de la variedad local "Criolla" derivan la mayor cantidad de preparaciones ( $82 \%$ ), lo que evidencia su importancia tanto por ser una de las variedades más apreciada como por estar presente en todos los espacios de cultivos. Importancia que se refleja en el relato Don RF (75 años) "Las criollas esas salen y son las más queridas, son lindas para el dulce, la mermelada, pal anchi, para todo". La etnovariedad "Deliciosa grande" (41\%) también resulta ser una alternativa para la preparación de diversos productos, seguida de las etnovariedades "Verde" (23\%) e "Inverniza" (23\%) respectivamente.
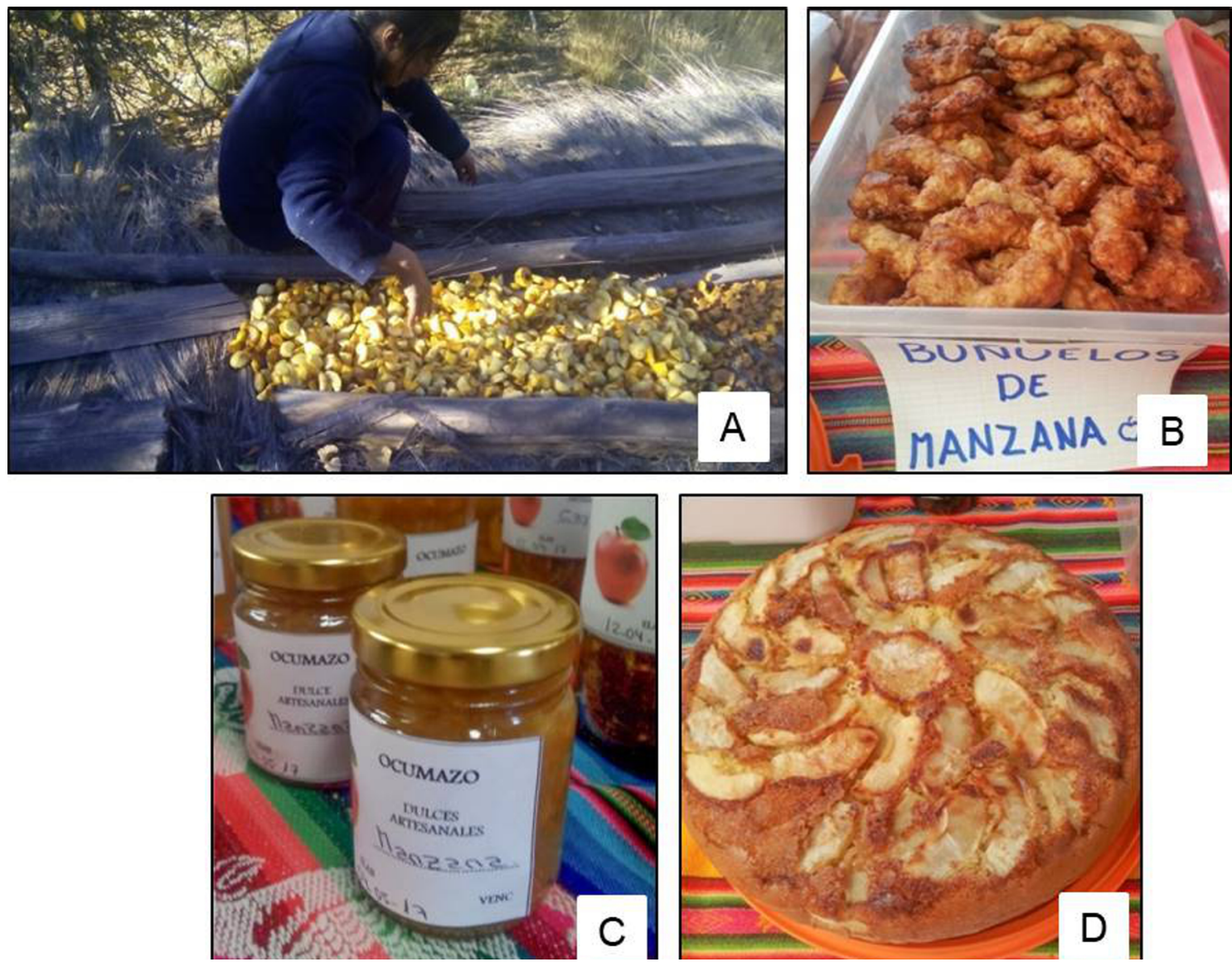

Fig. 4. Derivados de las manzanas de Ocumazo. A: Manzana deshidratada. B: Buñuelos de manzana. C: Dulce de manzana. D: Tarta de manzana. 


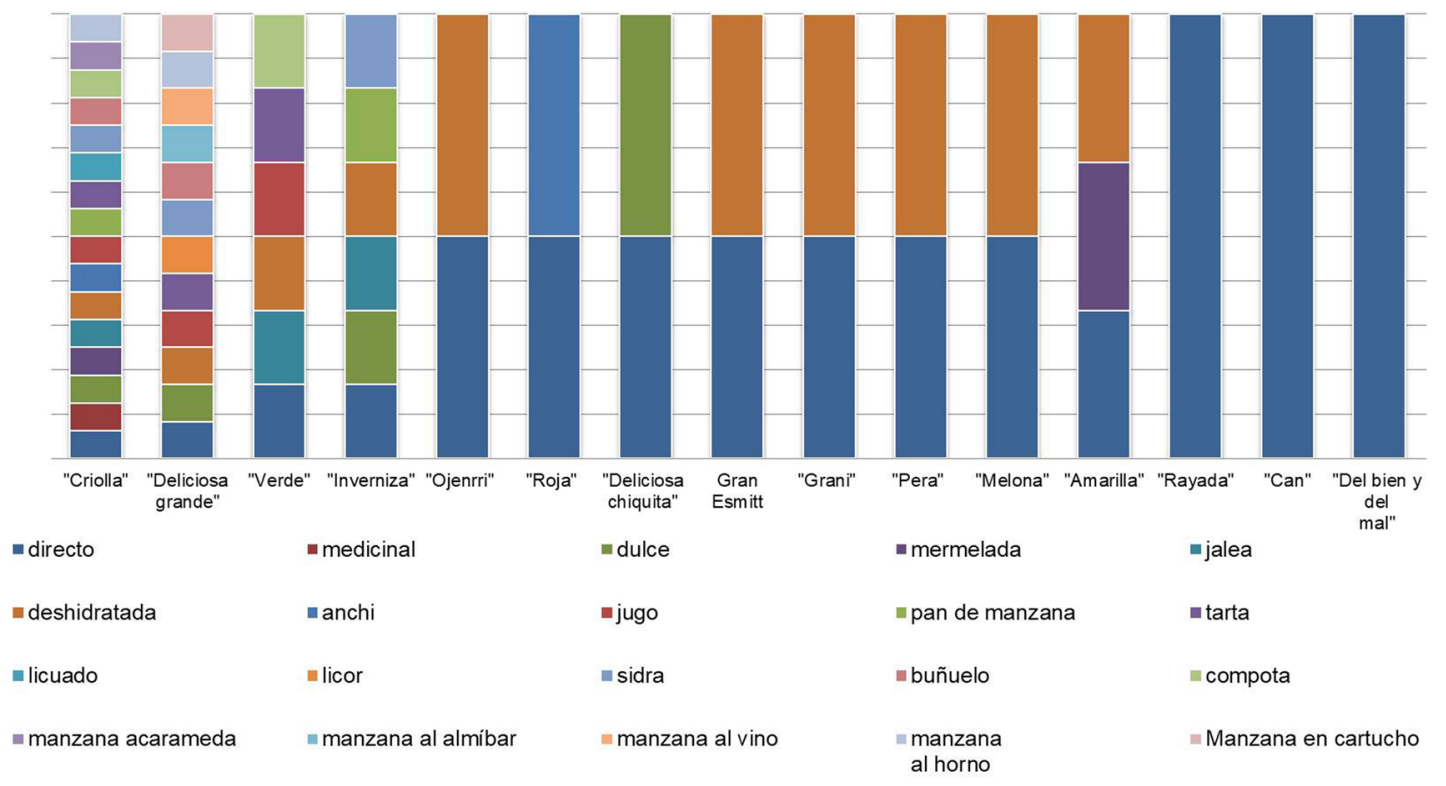

Fig. 5. Frecuencias de citas de uso de las etnovariedades de manzanas.

En instancias de comercialización la fruta también está presente en estado fresco o como algún derivado, conocidos localmente como "dulces de Ocumazo". Como se observa la Fig. 6. de las 15 etnovariedades definidas, 9 son las más empleadas en la elaboración de productos: "Criolla" $(60 \%)$, "Inverniza" (12\%), "Deliciosa grande" (8\%), "Verde" (8\%), "Deliciosa chiquita" (4\%), "Roja" (4\%), "Gran esmitt" (4\%), "Ojenrri" (4\%) y "Melona" (4\%).

De los resultados presentados se desprende que la diversidad de preparaciones depende con mayor frecuencia de las etnovariedades autóctonas ("Criolla" e "Inverniza"). Por otro lado, se puede establecer que existe una relación entre las preparaciones y la frecuencia en el uso de las etnovariedades (Fig. 5 y 6), coincidiendo también con las que resultan de ingresar a la comunidad aproximadamente hace 100 años. Cuando se indagó entre los entrevistados quienes fueron los encargados de transmitir sobre el uso y la elaboración de los preparados de "manzana", la respuesta común a todos fue que aprendieron de sus padres y abuelos, y que con el paso del tiempo lo fueron perfeccionando con la ayuda de técnicos.

Entre las novedades de preparados se encuentra la elaboración de sidra. Esta propuesta innovadora tiene como objetivo recuperar y revalorizar aquellas variedades antiguas y poco propagadas, como es el caso de la etnovariedad "Inverniza", situación que expresa doña MF (años) "ya estaba descartada

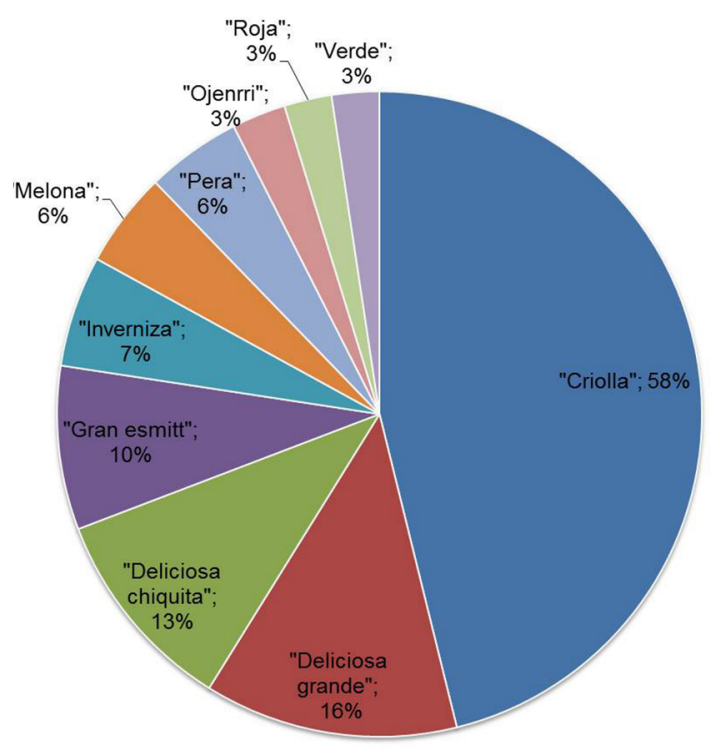

Fig.6. Frecuencia de citas de las etnovariedades empleadas en la elaboración de dulces artesanales de Ocumazo. 
y ahora la van apreciar más a esa porque sirve para la sidra. Se han hecho las plantas viejas y nosotros ya no hemos trasplantado porque vimos que no tenía salida", también lo manifiesta don HF (57 años) "la que a nosotros nos han dicho que es buenísima para la sidra, esa es la que madura al último, esa es la inverniza".

\section{Discusión}

Este trabajo permitió identificar y caracterizar la diversidad de "manzanas" en Ocumazo, la que está conformada por 15 etnovariedades. Este registro es menor al promedio expuesto en otros trabajos sobre la diversidad de la misma especie en distintos lugares de España, país donde existen evidencias que permiten comparaciones (Rivera-Núñez et al., 1997; Sierra del Rincón, 2010; Sanz-García, 2011; Egea-Fernández et al., 2014). Sin embargo, dicho número resulta relevante si se considera su reciente introducción y una primera presentación al estudio de etnotaxonomía y diversidad de "manzanas" en la Quebrada de Humahuaca.

En relación a la introducción de este cultivo, posiblemente al igual que el caso de los "duraznos" en Juella (Lambaré, 2015), las etnovariedades más antiguas de "manzana" pudieron ingresar durante el periodo Colonial (Sica, 2010). Por lo que la continuidad de este germoplasma introducido es resultado de las propiedades inherentes del cultivo que se aclimata a las condiciones ambientales de la Quebrada que resultan óptimas para su crecimiento y desarrollo (Schneider \&Scarbourough, 1980; Lang, 1989; Janick, 2002). Asimismo, su incorporación y resignificación dependen de las particularidades del grupo humano que selecciona y conserva las características deseables que se materializan y proyectan al paisaje biocultural al que se incluyen.

La conservación de las etnovariedades consideradas autóctonas y las foráneas, se basa en procesos culturales de manipulación, con los que se mantienen, adaptan y/o criollizan como el caso de algunos de los maíces en el NOA Ramos et al. (2013). La preferencia de una nueva etnovariedad por parte de los productores queda definida en parte a nuevas necesidades, usos, beneficios y demandas, siendo una valoración otorgada por la comunidad. En este sentido se puede entender el proceso de apropiación y resignificación de este cultivo como lo plantean Hilgert et al. (2014), es decir la decisión de incorporar elementos ajenos, debe entenderse en el marco de las cosmovisiones de estos grupos nativos que se ven influenciados por una incesante dinámica social e histórica, donde el poblador local participa activamente, ya sea rechazando, incorporando, resignificando o abandonando costumbres -o partes de su costumbres-. Dentro de ese marco cultural, al igual que la apropiación de los "duraznos" en la Quebrada y los "cítricos" en el NEA (Stampella et al., 2014), estos frutales originariamente foráneos se convierten en elementos identitarios que contribuyen a la definición de las costumbres y prácticas cotidianas de una comunidad.

Respecto a la popularidad compartida de la etnovariedad "Criolla", en coincidencia a lo ya expresado en Lambaré et al. (2015) y Artieda-Rojas et al. (2017), la misma probablemente se explique por su temprana incorporación en los circuitos de intercambios (trueques y cambalaches) como recurso para obtener divisas (sinónimo de dinero) de otras zonas de la Quebrada y de la región. Una situación contraria está ocurriendo con las otras tres etnovariedades ("Pera", "Melona", "Inverniza") que si bien son significativas por formar parte del patrimonio agrícola local, su representación en los espacios de cultivos e instancias de comercialización son bajas, y el uso de la frutas se limita al consumo familiar y en la elaboración de algunos derivados como sucede con "Inverniza".

En el trabajo de Egea-Fernández et al. (2014) se hace mención de la recuperación de una variedad tradicional de "manzana" llamada "Pero de Cehegin" en Chile. Esto se desarrolló a partir de un proyecto cuyo objetivo fue destacar sus cualidades $\mathrm{y}$ valoraciones, así como identificar y recuperar variedades de "manzana chilota" que poseen una antigua historia en la zona desde período de la conquista y colonización hispana de Chile (Salamanca, 2017). De forma similar en Ocumazo, la generación de un proyecto fruti-hortícola iniciado por los mismos productores, con la ayuda de organizaciones nacionales que trabajan en la zona, buscan revalorizar la diversidad de "manzanas", principalmente de aquellas etnovariedades menos demandadas, como es el caso de la "Inverniza", que posee cualidades específicas para la producción de sidra como alternativa comercial. Esta variedad local dejó de propagarse en los espacios de cultivos situación que se observa en la presencia de escasos 


\section{S. Villalba y D. A. Lambaré - Las manzanas en Ocumazo (Jujuy): usos y percepciones}

ejemplares de manzanos de "Inverniza" y en el relato de los pobladores. El desarrollo de estos proyectos locales promueve, además de la recuperación del cultivo de la etnovariedad, la diversificación de usos en base a la demanda local con el objetivo de buscar nuevos destinatarios y la ampliación de la oferta gastronómica de la comunidad.

En el presente análisis se consideran caracteres diferenciales de cada etnovariedades, que a su vez definen los criterios, descriptores o atributos locales utilizados para su clasificación. Estos criterios han sido mencionados en otros estudios referidos a la especie, Rivera-Núñez et al. (1997), citaron caracteres organolépticos (morfológicos y sensoriales) y agronómicos (fecha de maduración), así como el uso que se les asigna a las variedades identificadas. Sanz-García (2011) destaca la utilización específicamente del color, forma, tamaño del fruto, textura de la piel, sabor y de igual manera la fecha de maduración. No solo para el caso de este frutal se utilizan dichos descriptores, sino que también se registra su uso e importancia para la caracterización de otros cultivos como "duraznos", "citrus", "melones", "pitaya", "maíz" (Rosales-Bustamante et al., 2009; Martín, 2010; Lambaré \& Pochettino, 2012; Ramos et al., 2013; Stampella et al., 2014). De acuerdo a las menciones registradas, las características al estado vegetativo resultan poco relevantes. Los entrevistados que citaron algún criterio relacionado (como la forma y tamaño de la hoja y porte de la planta) lo hacen estableciendo la diferencia entre las autóctonas (específicamente la "Criolla") y las etnovariedades de incorporación reciente. Stampella (2016) hace referencia que el aroma, forma de las hojas y el porte de la planta son descriptores locales que se mencionan para el reconocimiento y distinción de las etnotaxa de Citrus.

Asimismo, los atributos locales que definen a cada etnovariedad son acompañados de descripciones personales o anecdóticas que refleja la consideración de esta especie cultivada como antropizada, es decir un recurso foráneo que sufrió un proceso de naturalización y/o apropiado y luego de resignificación Hilgert et al. (2014). Esta valoración representa una de las formas en que el poblador local se relaciona con su cultivo y lo define como parte de su paisaje biocultural.

Entre las etnovariedades nombradas, la "Inverniza" posee características que permiten su diferenciación con las demás, como la morfología (epicarpo grueso y sedoso), el carácter sensorial (al cosechar sabor ácido), y la duración postcosecha (necesita un periodo de almacenamiento de 7 a 8 meses para que adquiera el dulzor). Estas se comparten con los registros de RiveraNúñez et al. (1997) y Sanz-García (2011) para el grupo de "manzanas" denominadas "peros", especialmente para la etnovariedad "Pero de alcuza" conocido también como "Pero de invierno". Según lo descripto por estos autores, los agricultores depositan las "manzanas" en sótanos o despensas para que la fruta alcance su madurez y sabor adecuado. De forma similar en el área de estudio se utilizan trojas (hornos de barro con piso de paja), el que constituyen un lugar especialmente construido para mantener condiciones necesarias para el almacenamiento de la fruta cosechada y su conservación durante todo el invierno. En el ámbito andino, el empleo de troja, o troje, resulta una estrategia de almacenamiento que se practica desde la antigüedad y en cierto momento del calendario agrícola para preservar -por ejemplo- las "semillas" (para el caso del "maíz" y las papas) que se emplearan en el próximo ciclo productivo (Hilgert, 1998; Ramos, 2009). Asimismo, otra característica que permite su comparación, es la presencia de una piel gruesa, lo que aporta mayor duración cuando la fruta se almacena (Sánchez, 2017).

En cuanto a los usos (18), se constató una amplia riqueza de categorías nombradas por los pobladores locales, que engloba consumo directo o en fresco y elaborados, contrariamente a lo citado en la bibliografía de referencia (RiveraNúñez et al., 1997; Sierra del Rincón, 2010; Sanz-García, 2011) donde se destacan pocos productos en base a la fruta como postre verde, sidra, repostería, manzana asada, frita o cocida en vino o manteca y compota. Esta diferencia permite corroborar que los ocumaceños han logrado del conocimiento adquirido y transmitido, así como de la práctica cotidiana, diferentes formas de consumo y conservación de las etnovariedades de acuerdo a las particularidades que presenta cada una de ellas. Una de las costumbres que se realizan desde la antigüedad para la conservación y asegurar la presencia de ciertos alimentos en las distintas estaciones del año, es la elaboración de deshidratados. Estas preparaciones pueden realizarse por las condiciones microclimáticas 
de los valles secos, siendo uno de los productos que característicos y de importante demanda en las ferias locales de la quebrada de Humahuaca (Lambaré, 2015).

\section{Conclusiones}

Esta presentación da continuidad al estudio en la Quebrada de Humahuaca de las plantas cultivadas desde una perspectiva etnobotánica. Su realización permitió identificar un total de 15 etnovariedades de "manzana" cultivadas en Ocumazo. Datos que resultan una primera mención de la etnotaxonomía del cultivo. Esta diversidad se organiza y presenta en categorías éticas y quedan definidas desde criterios émicos, propios del productor local, por lo que a partir de su estudio se da a conocer lo que el productor de Ocumazo percibe de este cultivo foráneo. Las etnovariedades son reconocidas desde distintos criterios, descriptores o atributos como los organolépticos y de uso, por citar algunos de relevancia $\mathrm{y}$, se unen a factores prácticossimbólicos que definen el rol de este recurso para la interpretación del paisaje biocultural que integran. Asimismo, se establece que la variabilidad descripta y -adaptada al ambiente/paisaje de altura-, revela una alta agrodiversidad, en relación a la que poseen otras comunidades quebradeñas y a otros cultivos cuya historia de ingreso y apropiación son similares.

Los emprendimientos que se desarrollan en la zona, como por ejemplo la elaboración de sidra, propiciaron una revaloración de etnovariedades que se encontraban olvidadas, ampliando sus usos y su consideración como alternativa económica. Esto define el rol, o significado, de las diferentes etnovariedades, el cual se modifica de acuerdo a los cambios por lo que atraviesan las familias de la comunidad de Ocumazo.

El uso, la forma de selección, conservación, su consideración como parte de la diversidad de "frutas andinas" y la presencia en distintas instancias religiosas y de celebración, definen el relevante papel de este cultivo de origen euroasiático para el poblador local. El que, a su vez, le permite promover la conservación de las principales actividades económicas -como las agrícolas- $y$, a la vez, su autonomía alimentaria.

Asimismo, el estudio del CBT cobra relevancia, dado que su abordaje ofrece información valiosa que puede contribuir al desarrollo de estrategias de conservación in situ, a partir del conocimiento y promoción del mantenimiento de los espacios de cultivo bajo manejo tradicional.

\section{Contribución de los Autores}

Ambas autoras han realizado conjuntamente el diseño del trabajo, la interpretación de datos y redacción del manuscrito. El trabajo de campo lo realizó en su mayoría la primera autora como parte de su tesina de grado, con el asesoramiento de su directora la Dra. Lambaré.

\section{Agradecimientos}

A las autoridades del Centro Vecinal y productores de la comunidad de Ocumazo, por la autorización, hospitalidad y predisposición brindada durante el desarrollo del trabajo. A la Secretaria de Ciencia y Técnica y Estudios Regionales de la Universidad Nacional de Jujuy por la financiación de los Proyectos 08/A182 y A/B 043. A M. L. Pochettino y N. D. Vignale por sus aportes en distintas instancias del trabajo. A los evaluadores anónimos y a la editora Dra. Hilgert, sus observaciones enriquecieron el manuscrito.

\section{Bibliografía}

ALBUQUERQUE, U. P., R. F. PAIVA DE LUCENA \& L. V. F. CRUZ DA CUNHA. 2010. Métodos e técnicas na pesquisa Etnobiológica y Etnoecológica. Ed. Nuppea.

ALCORN, J. 1995. The scope and aims of ethnobotany in a developing world. En: Schultes, R. E. \& S. Von Reis, (eds.) Ethnobotany. Evolution of a discipline. Portland, Dioscorides Press.

ARTIEDA-ROJAS, J. R., R. I. MERA ANDRADE, M. S. MUÑOZ ESPINOZA \& P. S. ORTIZ TIRADO. 2017. El trueque como sistema de comercialización - Desde lo ancestral a lo actual. Uniandes Episteme 4: 288-300.

BERKES, F. 1999. Sacred ecology: traditional ecological knowledge and management systems. Philadelphia and London: Taylor \& Frances.

BERKES, F., J. COLDING \& C. FOLKE. 2000. Rediscovery of traditional ecological knowledge as 


\section{S. Villalba y D. A. Lambaré - Las manzanas en Ocumazo (Jujuy): usos y percepciones}

adaptative management. Ecological Applications 10: 1251-1262. https://doi.org/10.1890/10510761(2000)010[1251:ROTEKA]2.0.CO;2

BERLIN, B. 1992. Ethnobiological Classification. Principles of categorization of plants and animals in traditional societies. New Jersey: Princeton University Press.

BRAVO, M., M. I. ARTEAGA \& F. F. HERRERA. 2017. Bioinventario de especies subutilizadas comestibles y medicinales en el norte de Venezuela. Boletín Latinoamericano y del Caribe de Plantas Medicinales y Aromáticas 16: 347-360.

BRICKELL, C. D., C. ALEXANDER, J. C. DAVID, W. L. A. HETTERSCHEID, A. C. LESLIE, V. MALECOT, X. JIN \& J. J. CUBEY. 2009. International Code of Nomenclature for Cultivated Plants. Scripta Horticulturae 10: 1-184.

CASTRO, A. 2016. Chicha y Sidra de manzana en Chile (1870-1930): Manzanas con identificación de origen. RIVAR 3: 4-25.

CASTRO, A., F. M. FERNÁNDEZ \& D. U. GÓMEZ. 2018. Chicha de manzana de Chiloé: Historia épica de un producto típico, siglos XIX-XX. Revista Estudios Hemisferios y Polares 9: 1-24.

COTTON, C. M. 1998. Ethnobotany: Principles and applications. J. Wiley y Sons, England.

CRIVOS, M. 2010. Implicancias teóricas y metodológicas de las estrategias de investigación etnobotánica. En: VIGNALE, N. D. \& M. L. POCHETTINO (eds.), Avances sobre plantas medicinales andinas, pp. 5-10. San Salvador de Jujuy, CYTED.

DIFRIERI, H. 1978. Aspectos de la vegetación de altura y el Jardín botánico de altura. Entregas del Instituto Interdisciplinario Tilcara 2. Tilcara.

EGEA-FERNÁNDEZ, J. M., J. M. EGEA-SÁNCHEZ \& J. A. GALÁN. 2014. Variedades locales de frutales de pepita de la región de Murcia. Análisis preliminar. XI Congreso de SEAE: Agricultura ecológica familiar. Facultad de Biología, Universidad de Murcia. Murcia, pp. 11.

FOLGADO-FERNÁNDEZ, J. A., P. RAMIRO, A. M. CAMPÓN-CERRO, \& J. M. HERNÁNDEZMOGOLLÓN. 2017. Productos gastronómicos con identidad y desarrollo del destino turístico. Un estudio sobre rutas del queso en España. International Journal of Scientific Management and Tourism 3: 93-109.

GARCÍA-MORITÁN, M. \& M. B. CRUZ. 2011. Comunidades originarias y grupos étnicos de la provincia de Jujuy. Salta, Ed. del Subtrópico.
HARLAN, J. R. 1992. Crops \& Man. 2nd edition. Madison: American Society of Agronomy, Inc.

HERNÁNDEZ- BERMEJO, J. E. 2013. Cultivos infrautilizados en España: pasado, presente y futuro. Ambienta 102: 2-18.

HERRERO, J. 1964. Cartografía de Frutales de Hueso y Pepita. Capítulo IV: Apéndice de variedades: Manzano. Aula Dei. CSIC, Zaragoza, pp. 285.

HILGERT, N. I. 1998. Las plantas vinculadas con el ámbito doméstico y la subsistencia de los campesinos de la cuenca del río Zenta, Dpto. Orán, Prov. Salta. Tesis Doctoral. Facultad de Ciencias Exactas, Físicas y Naturales, Universidad Nacional de Córdoba, Córdoba. Argentina.

HILGERT, N. I., D. A. LAMBARÉ, N. D. VIGNALE, P. C. STAMPELLA \& M. L POCHETTINO. 2014. ¿Especies naturalizadas o antropizadas? Apropiación local y la construcción de saberes sobre los frutales introducidos en época histórica en el norte de Argentina. Rev. Biodivers. Neotrop. 4: 69-87.

JANICK, J. 2002. Wild apple and fruit trees of Central Asia. Horticultural Reviews 29, pp. 416.

LACOSTE, P., P. PSZCZOLKOWSKI, F. BRIONES, P. AGUILERA, F. MUJICA \& A. GARRIDO. 2015. Historia de la chicha de uva: un producto típico en Chile. IDESIA 33 (2): 87-96.

h t t p : / / d .doi.org/10.4067/S 0718 34292015000200011

LAMBARÉ, D. A. 2014. Manejo de variedades locales de Prunus persica (Rosaceae) en la Quebrada de Humahuaca, Argentina y su Relación con los Sistemas Agrícolas Tradicionales. Zonas Áridas 15: 128-147. http://hdl.handle.net/11336/35673

LAMBARÉ, D. A. 2015. Procesos locales de selección cultural en poblaciones de frutales de la familia Rosaceae originarias del Viejo Mundo utilizadas por comunidades rurales del noroeste argentino. Tesis Doctoral, Universidad Nacional de La Plata, La Plata. Argentina.

LAMBARÉ, D. A. \& M. L. POCHETTINO. 2012. Diversidad local y prácticas agrícolas asociadas al cultivo tradicional de duraznos Prunus persica (Rosaceae), en el Noroeste de Argentina. Darwiniana 50: 174-186. https://www.jstor.org/stable/41825707

LAMBARÉ, D. A., N. D. VIGNALE \& M. L. POCHETTINO. 2015. Las ferias y festivales regionales como instancia de reafirmación del patrimonio biocultural en la Quebrada de Humahuaca (Jujuy, Argentina): el intercambio de duraznos (Prunus persica). Gaia Scientia. Edição 
especial Etnobiologia na Argentina 9: 7-16. http://www.periodicos.ufpb.br/ojs2/index.php/gaia/ article/view/27242

LANG, G. A. 1989. Dormancy-models and manipulations of environmental physiological regulation. In: Wright, C.J. (Ed.), Manipulation of Fruiting. Butterworths, pp. 79-98, London.

LUNA-MORALES, C.DEC.2002.Ciencia, conocimiento tradicional y etnobotánica. Etnobiología 2: 120-135.

MARTIN, G. 2001. Etnobotánica. Manuales de Conservación Serie Plantas y gente. WWFUNESCO. Nordan-Comunidad, Montevideo.

MARTÍN, S. E. 2010. Caracterización etnobotánica, agro-morfológica, sensorial, física-química, nutricional y molecular de las variedades locales de Melón de Villaconejos. Tesis Doctoral, Universidad Politécnica de Madrid, Madrid. España.

MUÑOZ, N. G. 2014. Estudio de una iniciativa de turismo comunitario asociada a pueblos originarios en el norte argentino: la experiencia Ocumazo, Jujuy, Argentina. Repositorio Digital del Ministerio de Turismo de Argentina, pp. 19.

PAOLI, H., A. R. BIANCHI, C. E. YAÑEZ, J. N. VOLANTE, D. R. FERNÁNDEZ, M. C. MATTALÍA \& Y. E. NOÉ. 2002. Recursos hídricos de la Puna, valles y bolsones áridos del Noroeste Argentino. Convenio INTA EEA Salta-CIED, pp. 274.

PEARREGAARD, K. 1994. Más allá del dinero: trueque y economía categorial de un distrito en el valle del Colca. Anthropologica 11: 211-251.

PEREIRA-LORENZO, S., J. ASCASÍBAR-ERRASTI, A. M. RAMOS-CABRER \& J. PIÑEIRO-ANDIÓN. 2001. Colección de cultivares autóctonos gallegos de manzano (Malus $x$ domestica) del Banco de Germoplasma de Mabegondo. Monografía INIA, Serie Agricultura, pp. 454.

POCHETTINO, M. L. \& V. LEMA. 2008. La variable tiempo en la caracterización del conocimiento botánico tradicional. Darwiniana 46: 227 - 239. https://www.jstor.org/stable/23228355

RAMOS, R. S. 2009. Factores culturales, ambientales $\mathrm{y}$ de manejo involucrados en la pérdida $\mathrm{y} / \mathrm{o}$ conservación de variedades criollas de maíces en la comunidad rural de Caspalá, Provincia de Jujuy. Tesina de grado. Universidad Nacional de Jujuy, Jujuy. Argentina.

RAMOS, R. S., N. I. HILGERT \& D. A. LAMBARÉ. 2013. Agricultura tradicional y riqueza de maíces (Zea mays). Estudio de caso en Caspalá, provincia de
Jujuy, Argentina. Bol. Soc. Argent. Bot. 48: 607-621. ht t p :// www.botanicargentina.com.ar/ boletin/48-4/22_ramos.pdf

RIVERA-NÚÑEZ, D., C. OBÓN DE CASTRO, S. RÍOS-RUIZ, C. S. FERNÁNDEZ, F. MÉNDEZCOLMENERO, A. VERDE-LÓPEZ \& F. CANOTRIGUEROS. 1997. Las variedades tradicionales de frutales de la Cuenca del Río Segura. Catálogo Etnobotánico (1): Frutos secos, oleaginosos, frutales de hueso, almendros y frutales de pepita. Servicio de Publicaciones, Universidad de Murcia, pp. 359.

ROSALES, R. P. D. 1877. Historia general del reyno de Chile. Flandes Indiano. Tomo I, Valparaíso, Imprenta del Mercurio.

ROSALES-BUSTAMANTE, E. P., C. DEL C. LUNA-MORALES \& A. CRUZ-LEÓN. 2009. Clasificación y selección tradicional de pitaya (Stenocereus pruinosus (Otto) Buxb.) en Tianguistengo, Oaxaca y variación morfológica de cultivares. Revista Chapingo Serie Horticultura 15: 75-82.

SALAMANCA, F. M. 2017. Recuperación de antiguas variedades de manzanas chilotas. Instituto de Producción y Sanidad Vegetal de la Facultad de Ciencias Agrarias. Universidad Austral de Chile [online]. Disponible en: https://agrarias. uach.cl/recuperacion-de-antiguas-variedades-demanzanas-chilotas. [Acceso: 13 de junio de 2018].

SÁNCHEZ, E. 2017. Valoración de variedades tradicionales hortícolas para su uso en Agricultura Ecológica. Jornada de exposición de variedades tradicionales de tomate conservadas en Bagerim. Banco de Germoplasma del IMIDA. Instituto Murciano de Investigación y Desarrollo Agrario y Alimentario. Alberca, Murcia. 25 pp.

SANZ-GARCÍA, I. 2011. Estudio sobre conocimiento campesino en relación con el manejo de las semillas en una comarca de interés agroecológico: la sierra de Huelva. Tesis de Maestría, Universidad Internacional de Andalucía. España.

SCHNEIDER, G. W. \& C. C SCARBOUROUGH. 1980. Cultivo de árboles frutales. Compañía Editorial Continental S.A., pp. 154. México.

SHANLEY, P., M. CYMERYS, M. SERRA \& G. MEDINA. 2012. Frutales y plantas útiles en la vida amazónica. Organización de las Naciones Unidas para la Alimentación y la Agricultura. Centro para la Investigación Forestal Internacional y Pueblos y Plantas Internacional. Roma. 


\section{S. Villalba y D. A. Lambaré - Las manzanas en Ocumazo (Jujuy): usos y percepciones}

SICA, G. 2010. Del tráfico caravanero a la arriería colonial indígena en Jujuy. Siglos XVII y XVIII. Revista Transporte y Territorio 3: 23-39.

SIERRA DEL RINCÓN. 2010. Variedades tradicionales de frutales de la Reserva de la Biosfera Sierra del Rincón. [online]. Disponible en: http://www. sierradelrincon.org/pdf/publicaciones/Catalogo de_Frutales_en_la_Sierra_del_Rincon.pdf. htm [Acceso: 20 Marzo 2019].

STAMPELLA, P. C. 2015. Historia local de los cítricos (Citrus L., Rutaceae) del viejo mundo asilvestrados en el corredor de las antiguas misiones jesuíticas de la provincia de misiones (Argentina). Caracterización desde una perspectiva interdisciplinaria. Tesis Doctoral, Universidad Nacional de La Plata, La Plata. Argentina.

STAMPELLA, P. C. 2016. Local variability of citrus (Citrus L., Rutaceae) in pluricultural enclaves in the South of Misiones (Argentina): Diversity, uses and perception, and classification of variability. Journal of Ethnobiology 36: 637-657. https://doi.org/10.2993/0278-0771-36.3.637
STAMPELLA, P. C., D. A. LAMBARÉ, N. I. HILGERT \& M. L. POCHETTINO. 2013. What the Iberic conquest bequeathed to us: the fruit trees introduced in argentine subtropic, their history and importance in present traditional medicine. Evidence-Based Complementary and Alternative Medicine. Article ID $868394,17 \mathrm{p}$. http://dx.doi.org/10.1155/2013/868394

STAMPELLA, P. C., G. DELUCCHI, H. KELLER \& J. A. HURRELL. 2014. Etnobotánica de Citrus reticulata (Rutaceae; Aurantioideae) naturalizada en la Argentina. Bonplandia 23: 151-162. https://www.jstor.org/stable/26413063

TOLEDO, V. 1990. The ecological rationality of peasant production. In: ALTIERI, M. \& S. HECHT (eds.), Agroecology and small-farm developmet, pp. 51-58. Boca Raton, CRC Press.

TOLEDO, V. 2002. Ethnoecology. A conceptual framework for the study of indigenous knowledge of nature. In: Stepp, R., F. Wyndham \& R. Zarger (eds.), Ethnobiology and biocultural diversity, pp. 511-522. University of Georgia.Athens, Georgia, USA. 
